УДК 655.3.022

\title{
ОБ'ЄКТИВНЕ ВИЗНАЧЕННЯ КУТА ВІДХИЛЕННЯ \\ ПРИСТРОЮ НАТЯГУ ПОЛОТНА ПАПЕРУ ТА ЙОГО СТАБІЛІЗАЦІЯ У РУЛОННИХ ДРУКАРСЬКИХ МАШИНАХ
}

\author{
๑ В. Ф. Морфлюк, д.т.н., доцент, НТУУ «КПІ», Київ, Україна
}

Рассмотрен способ статистического определения угла отклонения устройства натяжения полотна бумаги для рулонных печатных машин, обеспечивающий объективность и достоверность измерения в реальном масштабе времени с использованием цифровых средств измерения и обработки для прогнозированной стабилизации натяжения полотна бумаги.

The method of the statistical determination of the angle of rejection of device of pull of paper linen is considered for roll printingpresses, providing objectivity and authenticity of measuring in the real scale of time with the use of digital facilities of measuring and treatment for the forecast stabilizing of pull of paper linen.

Постановка проблеми

Якість друкованої продукції при можливих змінах у перехідних режимах роботи багатосекційних рулонних друкарських машин в значній мірі залежить від натягу полотна паперу стрічкоживільного та стрічконамотувального пристроїв, що вимагає розробку нових методів, підходів та алгоритмів для побудови процесів визначення та стабілізації натягу полотна у реальному масштабі часу.

Тенденції процесів визначення та стабілізації натягу полотна стрічкоживильного та стрічконамотувального пристроїв в сучасних умовах повинні будуватися на методах статистичної обробки результатів вимірювання та засобах комплексної автоматизації процесів визначення та прийняття рішень для керу- вання технологічними процесами [1-3, 5, 7], які забезпечують підвищення вірогідності та точності стабілізації натягу полотна.

Актуальним рішенням проблем комплексної автоматизації процесів $€$ застосування проблемної орієнтації програмнотехнічних засобів [2, 3, 8], які дозволяють описувати проблеми в термінах процесів вимірювання, аналізу та процесів управління, ефективність використання яких залежить від застосування апаратних та програмних засобів на основі цифрової обробки інформації, 3 можливістю виконання математичного аналізу.

Автоматизація процесу визначення та стабілізації натягу полотна у рулонних друкарських машинах [3, 7, 8] обумовлює інтеграцію та уніфікацію апаратних та програмних засобів пере- 
творення, вимірювання та стабілізації, що забезпечує створення єдиної інтегрованої системи для стабілізації технологічного процесу.

Це визначає напрямок дослідження процесів для забезпечення якості друкованої продукції рулонних друкарських машин за рахунок автоматизації процесів визначення та стабілізації натягу полотна, що є актуальною проблемою побудови сучасних систем автоматичного регулювання натягу полотна.

\section{Аналіз попередніх досліджень}

Результати моделювання процесів натягу полотна паперу для стрічкоживильного і стрічконамотувального пристроїв та стрічкопровідної системи в цілому, які наведені у роботах $[1,3,5,7]$ на основі математичного опису процесів та їх аналізу, свідчать що вони мають принципове значення для проектування, побудови та управління процесами у рулонних друкарських машинах.

Аналіз методів визначення натягу полотна паперу стрічкоживильного та стрічконамотувального пристроїв та ї математичного моделювання показані у роботах [1-3], але не показано підходів до статистичного визначення натягу полотна у рулонних друкарських машинах 3 використанням сучасних технічних засобів непрямого визначення натягу [9], що потребує розробки методів та засобів, які забезпечують вірогідність цифрового статистичного вимірювання натягу полотна при виявленні порушення нормального розподілення вимірів за рахунок об'єктивної обробки експериментальних вимірів та їх стабілізації у реальному масштабі часу.

\section{Мета роботи}

Розробка способу цифрового статистичного вимірювання кута відхилення пристрою натягу полотна паперу у рулонних друкарських машинах на основі аналізу нормального розподілу вимірювань за критерієм $\chi^{2}$ та корекції збійних значень вимірів на основі об'єктивної обробки експериментальних вимірів та їх стабілізації у реальному масштабі часу.

\section{Результати проведеного дослідження}

Стабілізація процесу натягу полотна паперу базується на сукупності апріорних та поточних даних про об'єкт регулювання та стан технологічного середовища, які надаються через засоби зв'язку та перетворення інформації та свідчить, що найбільш досконалою є система автоматичного управління натягом, яка складається з двох незалежних частин: гасіння високочастотних коливань натягу, які пов'язані зі зміною форми рулону паперу та низькочастотних коливань, тобто безпосередньо зміною натягу полотна паперу. Перша частина управління вирішуеться на основі амортизаторів та пристрою «плаваючого» валика, який разом з електричним перетворювачем застосовується як датчик у багатьох схемах вимірювання натягу $[1,3,9]$, а друга частина базується на визначенні натягу по- 
лотна паперу, який залежить від гальмівного моменту муфти або швидкості обертання двигуна намотки, його аналізу та стабілізації для підтримки у зазначених межах.

На основі визначених принципів побудови процесів управління натягом полотна паперу, які найшли застосування у вітчизняних та зарубіжних рулонних друкарських машинах, запропонована функціональна схема автоматичного цифрового визначення та стабілізації натягом полотна паперу рис. 1 при розмотуванні та намотуванні, для якої характерною рисою $€$ застосування аналого-цифрових перетворювачів (АЦП) для вимірювання натягу полотна $\left(\beta=f\left(F_{\text {нн }}\right), \alpha=f\left(F_{\text {нр }}\right)\right)$ на основі кута відхилення пристрою натягу, цифро-аналогових перетворювачів (ЦАП) для керування процесом стабілізації $\left(U_{1,2}=\right.$ $\left.=f\left(K_{\text {рег } 1,2}\right)\right)$, та EOM зі спеціальним програмним забезпеченням визначення й аналізу зна- чення натягу та для вибору напрямку стабілізації та безпосередньо засобів регулювання (частотного перетворювача, двигуна намотування $\left(\mathrm{V}_{\mathrm{g}}=\mathrm{f}\left(\mathrm{U}_{2}\right)\right)$ та гальмівного пристрою $\left(\mathrm{M}_{r}=\right.$ $\left.=\mathrm{f}\left(\mathrm{U}_{1}\right)\right)$, що наведено на рис. 1.

Для автоматизації процесу визначення натягу паперового полотна у запропонованій функціональній схемі застосовується вимірювання кутового переміщення «плаваючого» валика відносно початкового положення $[3,8,9]$, яке після перетворення у цифрову форму застосовується для аналізу та стабілізації натягом полотна паперу.

Приведена функціональна схема цифрового автоматичного визначення та стабілізації кута відхилення пристрою натягу полотна паперу у рулонних друкарських машин вимагає виконання наступних функцій для управління процесом:

- вимірювання кута відхилення пристрою натягу, який функціонально залежить від

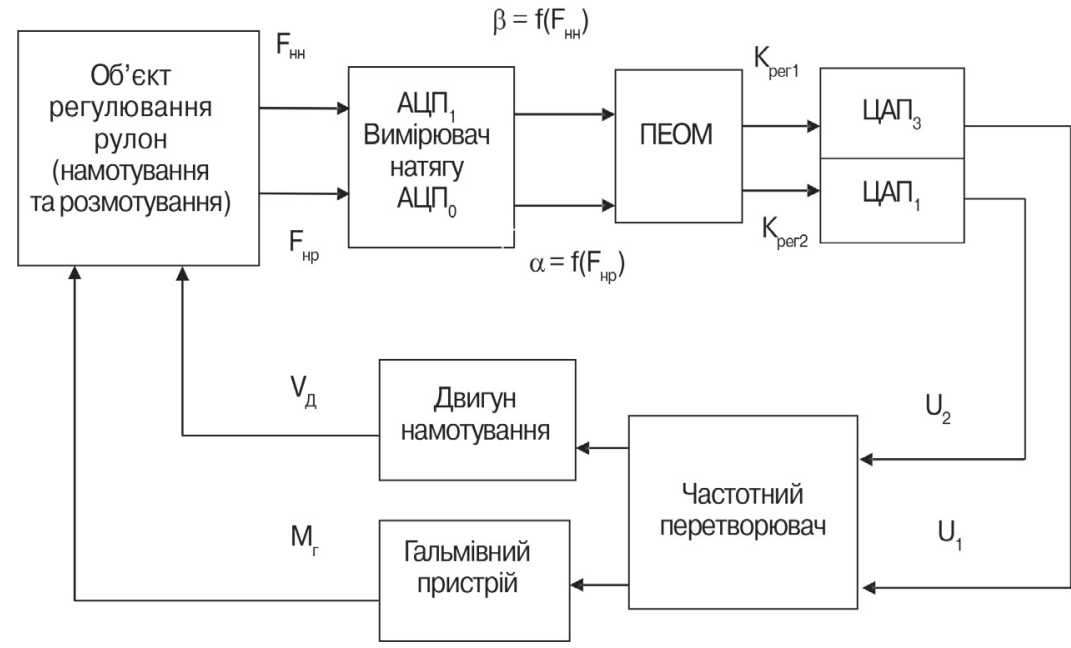

Рис. 1. Функціональна схема цифрового автоматичного визначення та стабілізації кута відхилення пристрою натягу полотна паперу 
значення натягу полотна паперу $\left(\alpha=\mathrm{f}\left(F_{\mathrm{H}}\right), \beta=\mathrm{f}\left(\mathrm{F}_{\mathrm{HH}}\right)\right)$;

- аналіз кута відхилення пристрою натягу від номінального значення для визначення напрямку регулювання гальмівним моментом електромагнітної порошкової муфти, або обертами двигуна розмотки, як виконавчих механізмів приводу рулону $\left(\mathrm{K}_{\text {рег }}=\mathrm{f}\left(\alpha-\alpha_{\text {ном }}\right), \mathrm{K}_{\text {рег }}=\right.$ $\left.=\mathrm{f}\left(\beta-\beta_{\text {ном }}\right)\right)$;

- визначення та подача керуючої напруги для безпосереднього управління приводом рулону (зміна гальмівного моменту $M_{г}$ електромагнітної муфти або швидкості обертів $\mathrm{V}_{\text {д дви- }}$ гуна намотування), завдяки частотному перетворювачу, для стабілізації натягу полотна паперу $\left(U_{1,2}=f\left(K_{\text {рег } 1,2}\right)\right)$.

Загальний алгоритм визначення та стабілізації кута відхи- лення пристрою натягу полотна паперу у рулонних друкарських машин показано на рис. 2.

Процес вимірювання базується на використані лінійного потенціометру ПтП21 (опір 32 ком, діапазон кута відхилення від $0^{\circ}$ до $330^{\circ}, 270^{\circ}, 210^{\circ}$, $180^{\circ}$ ), який встановлюється на осі пристрою визначення натягу полотна для пропорційного визначення кута його відхилення, 3 використанням АЦП за спеціальною схемою вимірювання під управлінням ПЕОМ, і записується у цифровий формі для подальшої обробки, аналізу та прийняття рішення для безпосередньої стабілізації натягом полотна.

Вимірювання виконується за допомогою дванадцяти розрядного двійкового АЦП у діапазоні

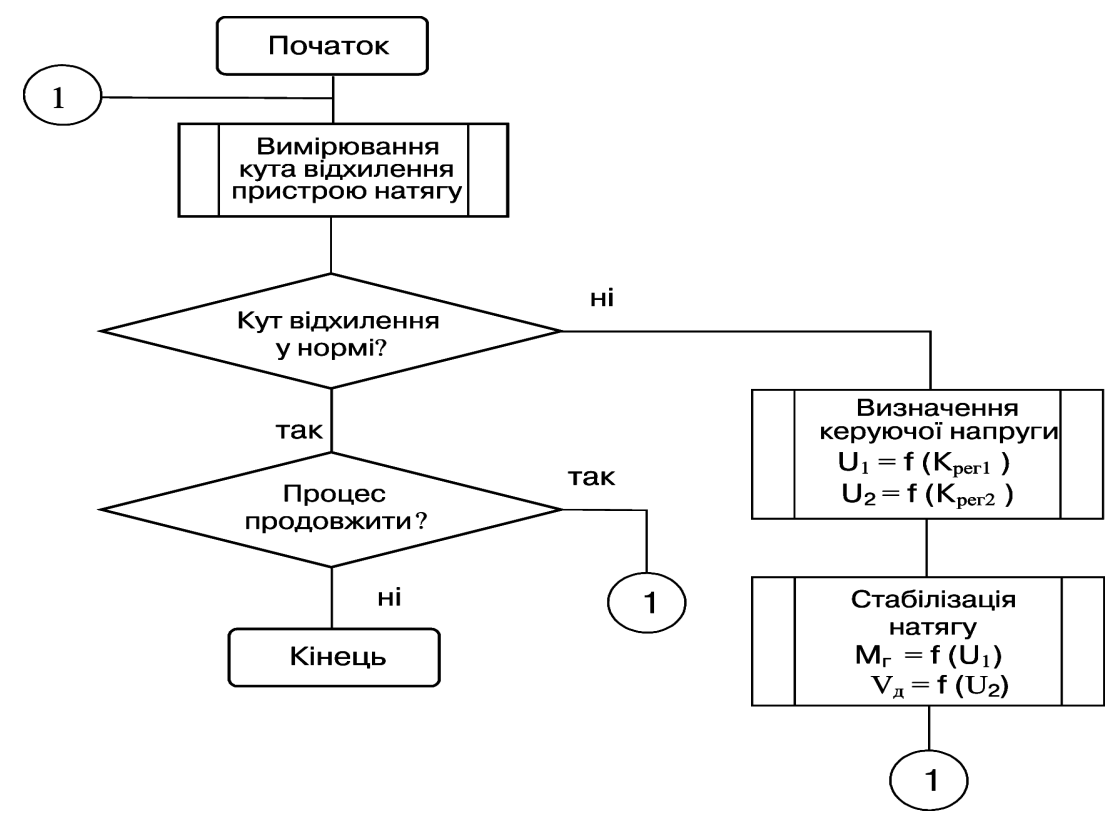

Рис. 2. Загальний алгоритм визначення та стабілізації кута відхилення пристрою натягу полотна паперу стрічкоживильного та намотувального пристроїв 
відхилення пристрою визначення натягу полотна, що відповідає діапазону вхідних значень опору лінійного потенціометру від 0 до $32 \cdot \alpha_{\text {виз }} / \alpha$ або від 0 до $32 \cdot \beta_{\text {виз }} / \beta$.

Вхідною інформацією АЦП є напруга $U$, яка має функціональну залежність $U=f(R)$ від значення опору лінійного потенціометру, який, в свою чергу, залежить від кута відхилення. На виході АЦП маємо цифровий код $\mathrm{K}_{\text {Ацп, }}$ який функціонально відповідає значенню кута відхилення.

$$
\begin{gathered}
\mathrm{K}_{\text {АЦП }}=\mathrm{f}\left(\mathrm{f}\left(\alpha_{\text {виз }}\right)\right) \\
\text { або } \mathrm{K}_{\text {АцП }}=\mathrm{f}\left(\mathrm{f}\left(\beta_{\text {виз }}\right)\right) .
\end{gathered}
$$

Відповідно з цим кут $\alpha_{\text {виз }}$ або

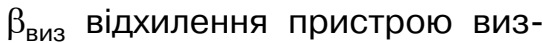
начення натягу обчислюється по наступних залежностях:

$$
\begin{gathered}
\alpha_{\text {виз }}=(\mathrm{R} \cdot \alpha) / 32, \beta_{\text {виз }}=(\mathrm{R} \cdot \beta) / 32 \\
\mathrm{U}=\left(\mathrm{U}_{\text {опор }} \cdot \mathrm{K}_{\mathrm{AЦП}}\right) / 2^{\mathrm{NA}}, \\
\alpha_{\text {виз }}=\mathrm{K}_{\text {АЦП }} \cdot\left(\alpha / 2^{\mathrm{NA}}\right), \\
\beta_{\text {виз }}=\mathrm{K}_{\text {АЦП }} \cdot\left(\beta / 2^{\mathrm{NA}}\right),
\end{gathered}
$$

де $\mathrm{K}_{\text {Ацп }}$ - значення кута відхилення $\alpha_{\text {виз }}$ у одиницях АЦП $;$; пропорційне значення кута відхилення $\alpha_{\text {виз }}$ або $\beta_{\text {виз }}$ в омах; $\bigcup_{\text {опор }}-$ опорна напруга схеми виміру опору пристрою визначення натягу $\left(Ц А \Pi_{0}\right) ; N A-$ кількість двійкових розрядів АЦП.

Процес регулювання натягом полотна залежить від значення кута відхилення від умовного нуля $(0,5 \alpha$ або $0,5 \beta)$. Тому для аналізу кута відхилення та оптимізації процесів автоматичного регулювання натягом полотна значення кута відхилення поділено на наступні діапазони, які визначають логіку стабілізації натягу: діапазон I - від $0^{\circ}$ до $0,05 \alpha^{\circ}$; діапазон II - від $0,05 \alpha^{\circ}$ до $0,5 \alpha^{\circ}-0,01 \alpha^{\circ} ;$ діапазон III від $0,5 \alpha^{\circ}-0,01 \alpha^{0}$ до $0,5 \alpha^{\circ}+$ $0,01 \alpha^{0}$; діапазон IV - від $0,5 \alpha^{0}+$ $0,01 \alpha^{\circ}$ до $\alpha^{\circ}-0,05 \alpha^{\circ}$; діапазон V - від $\alpha^{\circ}-0,05 \alpha^{\circ}$ до $\alpha^{\circ}$.

Регулювання натягом полотна виконується двигуном намотки, керованого частотним перетворювачем, на який подається керуюча напруга $U_{\mathrm{K}} 3$ ЦАП ${ }_{1}$. Вхідною інформацією ЦАП 1 рис. $1 €$ цифровий код, який відповідає значенню необхідної керуючої напруги для регулювання. Якщо цифро-аналоговий перетворювач має ND двійкових розрядів та діапазон вихідної напруги вибрано від Ов до Uв, то тоді цифровий код ке-

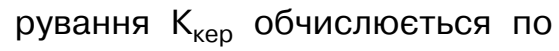
наступній залежності:

$$
\mathrm{K}_{\mathrm{Kep}}=2^{\mathrm{ND}} \cdot\left(1-\mathrm{U}_{\mathrm{K} /} \mathrm{U}_{\mathrm{B}}\right) \text {, }
$$

де $\mathrm{K}_{\text {кер }}$ - цифровий код керування; $U_{K}-$ керуючої напруги; ND - кількість двійкових розрядів ЦАП .

В залежності від визначеного значення кута відхилення на ЦАП 1 або ЦАП 2 формується напруга регулювання $U_{K}$, яка за допомогою частотного перетворювача подається на двигун для регулювання обертів двигуна намотування полотна паперу або для регулювання гальмівного моменту швидкості обертів рулону.

Якщо визначений кут відхилення пристрою визначення натягу полотна паперу дорівнює $\alpha_{\text {виз }}$ або $\beta_{\text {виз }}$, то обчислення значення керуючої напруги для регулювання двигуном намотки полотна за допомогою частот- 
ного перетворювача матиме наступний вираз:

$$
\begin{aligned}
& \mathrm{U}_{\mathrm{K}}=\left(1-\frac{\alpha}{\alpha}\right) \times \mathrm{U}_{\mathrm{B}} \quad \text { або } \\
& \mathrm{U}_{\mathrm{K}}=\left(1-\frac{\beta_{\text {виз }}}{\beta}\right) \times \mathrm{U}_{\mathrm{B}},
\end{aligned}
$$

де $\alpha, \beta-$ максимальний кут відхилення пристрою визначення натягу пристрою намотування або розмотування полотна паперу. Таким чином, використовуючи вказаний вираз, цифровий код регулювання $\mathrm{K}_{\text {кер }}$ обчислюється по наступній залежності:

$$
\begin{aligned}
& \mathrm{K}_{\text {кер }}=2^{\mathrm{ND}} \times\left(1-\frac{\alpha_{\text {виз }}}{\alpha}\right) \text { або } \\
& \mathrm{K}_{\text {кер }}=2^{\mathrm{ND}} \times\left(1-\frac{\beta_{\text {виз }}}{\beta}\right) .
\end{aligned}
$$

Статистичне визначення та аналіз кута відхилення пристрою натягу полотна паперу ґрунтується на найкращій оцінці $\mathrm{X}$, тобто $\mathrm{x}_{\mathrm{cp}}$, по результам $\mathrm{n}$ вимірів, якщо вони розподіленні у відповідності з законом Гауса $\mathrm{f}_{\mathrm{x}, \sigma}(\mathrm{X})$, та ширині очікуємого розподілення $\sigma$ :

$$
\begin{gathered}
X=x_{c p .}=\frac{1}{n} \sum_{i=1}^{n} x_{i}, \\
\sigma=\sqrt{\frac{\sum_{i=1}^{n}\left(x_{i}-x_{c p}\right)^{2}}{n-1}},
\end{gathered}
$$

де $\mathrm{x}_{\mathrm{i}}-$ значення кута відхилення у одиницях вимірювання АЦП; $\mathrm{n}$ - кількість вимірів.

Аналіз статистичного визначення натягу полотна паперу [4, 6-8] показуе, чи задовольняє фактичне розподілення експериментальних вимірювань гіпотезі, що результати розподіленні у відповідності з законом Гауса $\mathrm{f}_{\mathrm{x}, \sigma}(\mathrm{X})$ для оцінених раніше $X \mathrm{i} \sigma$. Для достовірного аналізу гіпотези застосовується критерій $\chi^{2}$, а для корекції аномальності експериментальних вимірювань використовується критерій Шовене, що забезпечує достовірність та точність визначення та стабілізації натягу полотна паперу.

\section{Висновки}

1. Автоматизація статистичного визначення кут відхилення пристрою визначення натягу полотна паперу дозволяє підвищити достовірність та точність визначення та стабілізації натягу полотна у рулонних друкарських машинах.

2. Застосування машино-залежної мови програмування для побудови засобів автоматизації процесів визначення та прийняття рішень для керування технологічним процесом надають можливість зменшити час на визначення натягу полотна паперу статистичним методом та забезпечують виконання процесів визначення та стабілізації натягу у реальному масштабі часу.

1. Дурняк Б. В. Стрічкопровідні системи рулонних ротаційних машин / Б. В. Дурняк. - К. : Атіка, 2002. - 292 с. 2. Казакевич В. В. Системы автоматического управления полиграфическими процессами / В. В. Казакевич, Э. И. Избицкий. - М. : Книга, 1978. - 341 с. 3. Ефимов М. В. Автоматизация технологических процессов полиграфии / М. В. Ефимов, Г. Д. Тол- 
стой. - М. : Книга, 1989. - 512 с. 4. Вентцель Е. С. Теория вероятностей / Е. С. Вентцель. - М. : Физ.-матем. литературы, 1958. - 464 с. 5. Морфлюк В. Ф. Автоматизація процесів контролю технологічних параметрів поліграфічного устаткування / В. Ф. Морфлюк // Друкарство. - 2001. № 1. - С. 34-35. 6. Тейлор Дж. Введение в теорию ошибок. Пер. с англ. / Дж. Тейлор. - М. : Мир, 1985. - 272 с. 7. Морфлюк В. Ф. Статистичне оцінювання та визначення натягу паперового полотнища у рулонних друкарських машин / В. Ф. Морфлюк // Друкарство. - 2003. - № 3(50). С. 62-64. 8. Морфлюк В. Ф. Автоматизована система дискретного регулювання натягу полотна паперу стрічкоживильного пристрою рулонних друкарських машин / В. Ф. Морфлюк, В.В.Чуркін // Технологія і техніка друкарства. Збірн. наук. праць Видав.-поліграф. і-ту НТУУ «КПІ». 2003. - № 2. - С. 88-93. 9. Патент № 68680 А, Україна. Флексографічна друкарська машина / Морфлюк В. Ф., Балабан О. Т., Войтович А. М., Никифорук Б. В., Чуркін В. В. - Чинний від 10.04.2007.

1. Durnjak B. V. Strichkoprovidni sistemi rulonnih rotatsijnih mashin / B. V. Durnjak. - K. : Atika, 2002. - 292 s. 2. Kazakevich V. V. Sistemi avtomaticheskoho upravlenija poligraficheskimi protsessami / V. V. Kazakevich, E. I. Izbitskij. - M. : Kniha, 1978. - 341 s. 3. Efimov M. V. Avtomatizatsija tehnolohicheskih protsessov poligrafii / M. V. Efimov, H. D. Tolstoj. - M. : Kniha, 1989. - 512 s. 4. Venttsel' E. S. Teorija verojatnostej / E. S. Venttsel'. - M. : Fiz.-matem. literaturji, 1958. - 464 s. 5. Morflyuk V. F. Avtomatizatsija protsesiv kontrolju tehnolohichnih parametriv poligrafichnoho ustatkuvannja / V. F. Morflyuk // Drukarstvo. - 2001. - \# 1. - S. 34-35. 6. Tejlor Dj. Vvedenije v teoriju oshibok. Per. s anhl. / Dj. Tejlor. - M. : Mir, 1985. - 272 s. 7. Morflyuk V. F. Statistichne otsinjuvannja ta viznachennja natjahu paperovoho polotnishcha u rulonnih drukars'kih mashin / V. F. Morflyuk // Drukarstvo. 2003. - \# 3(50). - S. 62-64. 8. Morflyuk V. F. Avtomatizovana sistema diskretnoho rehuljuvannja natjahu polotna paperu strichkozhivil'noho pristroju rulonnih drukars'kih mashin / V. F. Morflyuk, V. V. Churkin // Tehnolohija i tehnika drukarstva. Zbirn. nauk. prats' Vidav.-poligraf. i-tu NTUU «KPI». - 2003. \# 2. - S. 88-93. 9. Patent \# 68680 A, Ukraina. Fleksohrafichna drukars'ka mashina / Morflyuk V. F., Balaban O. T., Vojtovich A. M., Nikiforuk B. V., Churkin V. V. - Chinnij vid 10.04.2007.

Рецензент - О. М. Величко, д.т.н., професор, НТУУ «КПІ» 